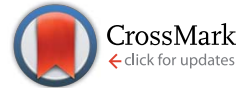

Cite this: Chem. Sci., 2016, 7, 6669

\title{
Ferrocenyl chiral bisphosphorus ligands for highly enantioselective asymmetric hydrogenation via noncovalent ion pair interaction $\uparrow$
}

\author{
Caiyou Chen, ${ }^{a}$ Heng Wang, ${ }^{a}$ Zhefan Zhang, ${ }^{a}$ Shicheng Jin, ${ }^{a}$ Songwei Wen, ${ }^{a}$ \\ Jianjian Ji, ${ }^{a}$ Lung Wa Chung, ${ }^{b}$ Xiu-Qin Dong ${ }^{\star a}$ and Xumu Zhang ${ }^{\star a b}$
}

\begin{abstract}
A new class of ferrocenyl chiral bisphosphorus ligand, Wudaphos, was developed, and exhibits excellent ee and activity (ee up to $99 \%$, TON up to 20 000) for the asymmetric hydrogenation of both 2-aryl and 2-alkyl acrylic acids through ion pair noncovalent interaction under base free and mild reaction conditions. Well-known anti-inflammatory drugs such as naproxen and ibuprofen together with the intermediate for the preparation of Roche ester and some bioactive compounds were also efficiently obtained with excellent ee. Control experiments were conducted and revealed that the ion pair noncovalent interaction and chain length played important roles.
\end{abstract}

Received 27th April 2016

Accepted 29th June 2016

DOI: $10.1039 / \mathrm{c} 6 \mathrm{sc01845a}$

www.rsc.org/chemicalscience

the ion pair interaction showed the strongest interaction. We anticipated that the strong ion pair noncovalent interaction can be utilized in the development of a new efficient catalytic system for asymmetric hydrogenation $(\mathrm{AH})$, wherein the substrates can interact with the catalyst strongly, accelerating the reaction rate to a large extent. However, only a few examples have been reported concerning of the strong ion pair noncovalent interaction and the substrate scope was limited. ${ }^{5}$

With regard to the utilization of the strong ion pair noncovalent interaction in the development of new chiral catalysts for $\mathrm{AH}$, we found that Ugi's amine is a privileged motif in which the dimethyl amine moiety can play as a proton acceptor which can interact with the acid substrates strongly through noncovalent ion pair interaction (Scheme 1). Moreover, the Ugi's amine motif can conveniently incorporate planar chirality, C-chirality and P-chirality into the catalytic system as exemplified by many efficient chiral ligands such as Josiphos, ${ }^{6}$ Walphos, ${ }^{7}$ Taniaphos, ${ }^{8}$ Bophoz, ${ }^{9}$ Mandyphos, ${ }^{10}$ TRAP, ${ }^{11}$ Trifer $^{5 a}$ and Chenphos. ${ }^{5 b}$ Herein, we report a new class of bisphosphorus ligands incorporating the Ugi's amine motif (Scheme 1). catalytic system utilizing attractive noncovalent interactions. ${ }^{4}$ As summarized by Jacobson et al. (Table 1), ${ }^{3}$ among the three representative noncovalent interactions, the steric repulsion is highly distance dependent $\left(1 / r^{12}\right)$ wherein weak interaction was observed with long distance. H-Bond interaction $\left(1 / r^{2}\right)$ and ion pair interaction $(1 / r)$ are relatively less distance dependent and

${ }^{a}$ College of Chemistry and Molecular Sciences, Wuhan University, Wuhan, Hubei 430072, P. R. China. E-mail: xumu@whu.edu.cn; xiuqindong@whu.edu.cn

${ }^{b}$ Department of Chemistry South University of Science and Technology of China, Shenzhen, 518055, P.R. China

$\dagger$ Electronic supplementary information (ESI) available. CCDC 1456993. For ESI and crystallographic data in CIF or other electronic format see DOI: 10.1039/c6sc01845a

Table 1 Distance dependencies of the representative noncovalent interactions

\section{Entry Noncovalent interaction Energy dependence on distance}

\begin{tabular}{|c|c|c|}
\hline 1 & Steric repulsion $\quad \xi-\mathrm{CH}_{3} \chi_{\mathrm{H}_{3} \mathrm{C}-\xi}$ & $1 / r^{12}$ \\
\hline 2 & H-bond & Complicated $\sim 1 / r^{2}$ \\
\hline & $\stackrel{\oplus}{\xi}-\mathrm{NH}_{3} \quad \stackrel{\ominus}{\mathrm{O}_{2}} \mathrm{C}-{ }^{-} \xi$ & $1 / r$ \\
\hline
\end{tabular}




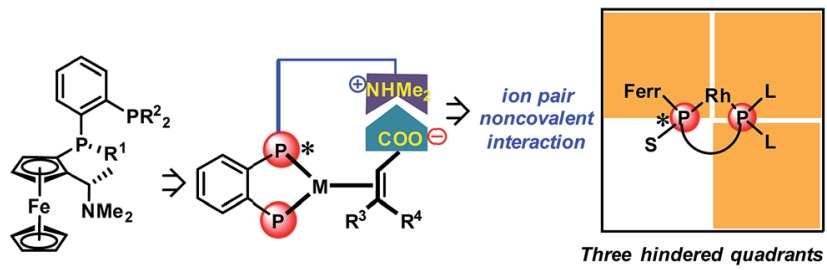

Scheme 1 The new ferrocenyl ligands and the corresponding model of the three hindered quadrants. $\mathrm{L}=$ large substituent, $\mathrm{S}=$ small substituent, and Ferr $=$ ferrocene

This type of bisphosphorus ligand possesses one chiral phosphine and the chiral Ugi amine moiety. Two large substituents of the non-chiral phosphine together with a ferrocene backbone block three quadrants, and the small substituent of the chiral phosphine makes the remaining quadrant open. This three blocked quadrant model is believed to have good chiral induction. ${ }^{12}$ Furthermore, the dimethyl amine unit in the ligand can be a proton acceptor and thus can interact with the acid substrates through noncovalent ion pair interaction. According to the above hypothesis, this catalytic system is believed to exhibit excellent enantioselectivity and activity in the $\mathrm{AH}$ of unsaturated acid substrates.

$\mathrm{AH}$ of 2-substituted acrylic acids will generate chiral $\alpha$-substituted propanoic acids which are important units that widely exist in pharmaceuticals and fine chemicals (Scheme 2). Good examples are the well-known non-steroid anti-inflammatory and analgesic drugs such as naproxen, ibuprofen and flurbiprofen, ${ }^{13}$ the esterification potent inhibitors 4 against the inflammatory phenotype of the cystic fibrosis (CF) lung disease ${ }^{14}$ the bioactive natural product 5 isolated from the Fusarium oxysporum which shows cytotoxicity against three human cancer cell lines PC-3, PANC-1 and A549, ${ }^{15}$ and artemisnin ${ }^{16}$ which is a famous drug against Plasmodium falciparum malaria that won the 2015 Nobel Prize in medicine. Furthermore, $\alpha$-substituted propanoic acid can also be used to prepare the synthetically important Roche ester, a well-known synthon in total synthesis. ${ }^{17}$ Although AH of 2-substituted acrylic acids was previously realized using chiral Ru catalysts, ${ }^{18}$ the reactions were limited by the generally required high pressure. Chiral $\mathrm{Rh}$ and Ir catalysts have also recently been reported to realize this valuable transformation. ${ }^{19}$ However, most of these catalytic systems need an equivalent base to neutralize the free acid. ${ }^{19}$

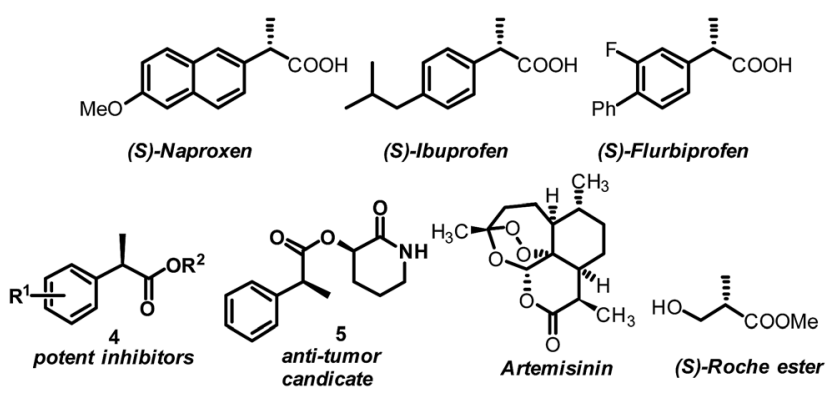

Scheme 2 Representative drugs and chemicals featuring the $\alpha$ substituted propanoic acid moiety.

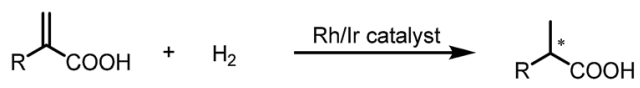

a) Previous work: equivalent base was essential

b) This work: direct hydrogenation through secondary interaction without any base

Scheme $3 \mathrm{AH}$ of 2-substituted acrylic acids

This method is non-direct and needs additional procedure to remove the base. Herein we report a ferrocenyl catalytic system that can finely utilize the free acid via the attractive noncovalent ion pair interaction to realize this valuable transformation in a direct and concise way without any base with $e e$ (enantiomeric excess) up to $99 \%$ and TON up to 20000 (Scheme 3).

\section{Results and discussion}

The new ferrocenyl bisphosphorus ligands we report herein can be easily synthesized in two-pot with very high diastereoselectivity ( $\mathrm{dr}>99: 1$ ) (Scheme 4). Starting from (S)-Ugi amine, a one pot sequential reaction gave 1 efficiently. Importantly, compound $\mathbf{1}$ was obtained as a single diastereomer as determined by NMR which makes the synthesis to be very simple and practical. The subsequent lithiation followed by treating with different chlorophosphines afforded the desired ligands L1-L5 in good yields. Moreover, the absolute configuration of $\mathbf{L 1}$ was determined using X-ray spectrum analysis as $\left(S_{\mathrm{c}}, R_{\mathrm{FC}}, S_{\mathrm{p}}\right) \cdot{ }^{20}$ Importantly, ligands $\mathbf{L 1}-\mathbf{L} 5$ are all highly air stable even when stored under air for more than one year.
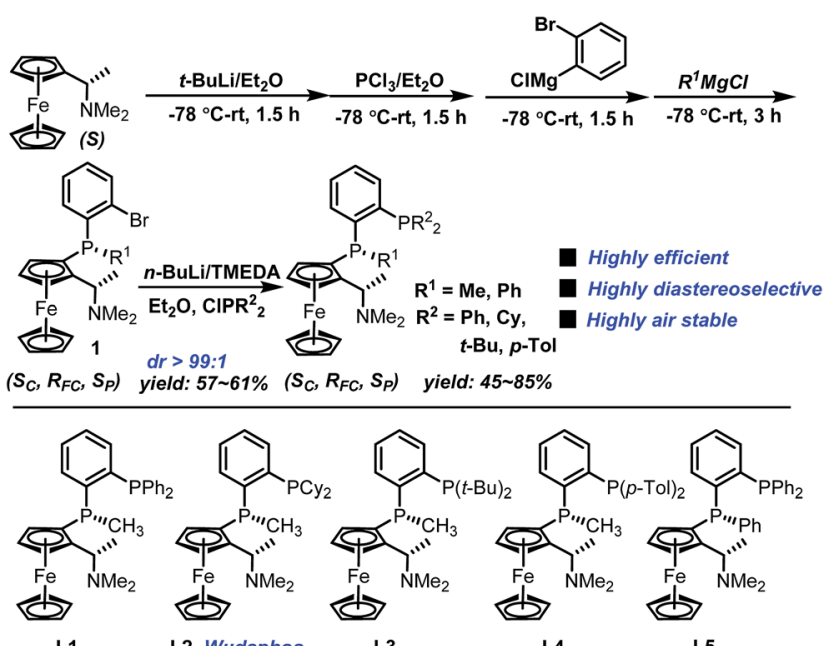

$\begin{array}{ccccc}\text { L1 } & \text { L2, Wudaphos } & \text { L3 } & \text { L4 } & \text { L5 } \\ \text { yield: } 83 \% & \text { yield: } 85 \% & \text { yield: } 45 \% & \text { yield: } \mathbf{7 2} \% & \text { yield: } 75 \%\end{array}$

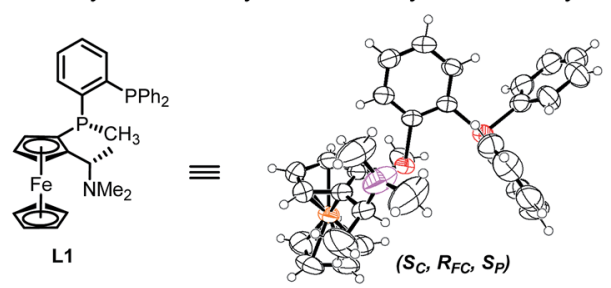

Scheme 4 Synthesis of the ferrocenyl new bisphosphorus ligands. 
With ligands L1-L5 in hand, AH of 2-substituted acrylic acids was initiated by evaluating ligand effects using 2-phenyl acrylic acid 2a as a model substrate (Table 2). We were pleased to find that the substrate was all smoothly converted except when using L5 as the ligand (Table 2, entry 5) in the absence of any base. The hydrogenation results highly depended on the ligand structure. With L1, a good ee was obtained (Table 2, entry 1). Changing the phenyl group in $\mathbf{L 1}$ into a cyclohexyl group (L2, Table 2, entry 2), the ee significantly increased to $98 \%$. However, to our surprise, further changing the phenyl group into the steric bulky $t$-butyl group resulted in a very low $e e$ and the product configuration was changed from $(S)$ to $(R)(\mathbf{L} \mathbf{3}$, Table 2 , entry 3 ). This is probably due to the much too big steric hindrance of the $t$-butyl group which influences the noncovalent ion pair interaction between the ligand and substrate. Further changing the phenyl group into the $p$-tolyl group resulted in a decreased $e e$ (L4, Table 2, entry 4). Using $\mathbf{L} \mathbf{5}$ as a ligand with a phenyl group instead of a methyl group attached to the chiral phosphine, the ee dropped significantly (L5, Table 2 , entry 5). This result corresponds to the hypothesis that we made that the ligand should have three blocked quadrants and make the remaining quadrant open in order to get good enantioselectivities (Scheme 1). In terms of reactivity and enantioselectivity, $\mathbf{L} 2$ was selected as the optimum ligand for further investigation. Due to the remarkable performance, herein we name L2 Wudaphos.

Subsequently, the substrate scope of the AH of 2-substituted acrylic acids was investigated using the optimum ligand Wudaphos under the best reaction conditions (for the screening of the reaction conditions and the discussion of the solvent effects, see ESI $\dagger$ ). As listed in Table 3, 2-aryl acrylic acids were efficiently hydrogenated with excellent enantioselectivities under mild reaction conditions in the absence of any base regardless of whether the substituents on the phenyl ring were

Table 2 Ligand effect in the asymmetric hydrogenation of 2-phenyl acrylic acid $^{a}$

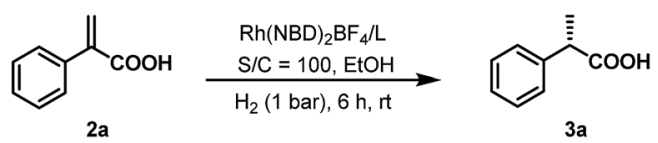

\begin{tabular}{lllll}
\hline Entry & Ligand & Conv. ${ }^{b} \%$ & $e e^{c_{\%}}$ & Configuration $^{d}$ \\
\hline 1 & L1 & $>99$ & 84 & $(S)$ \\
2 & Wudaphos & $>99$ & 98 & $(S)$ \\
3 & L3 & $>99$ & 33 & $(R)$ \\
4 & L4 & $>99$ & 74 & $(S)$ \\
5 & L5 & 67 & 57 & $(S)$
\end{tabular}

${ }^{a}$ The reaction was conducted in a $0.1 \mathrm{mmol}$ scale in $1 \mathrm{~mL}$ of EtOH, $\left[\mathrm{Rh}(\mathrm{NBD})_{2}\right] \mathrm{BF}_{4}(\mathrm{NBD}=$ norbornadiene $)$ was used as metal precursor, $\mathrm{S} / \mathrm{C}=100, \mathrm{~L} / \mathrm{Rh}=1.1: 1$, temperature $=\mathrm{rt}, \mathrm{H}_{2}$ pressure $=1$ bar, reaction time $=6 \mathrm{~h} .{ }^{b}$ Substrate conversion, determined using ${ }^{1} \mathrm{H}$ NMR. ${ }^{c}$ Enantiomeric excess of 3a, determined using chiral HPLC after treating 3a with $\mathrm{CH}_{2} \mathrm{~N}_{2} .{ }^{d}$ Configuration of $3 \mathrm{a}$, determined by comparing the optical rotation data with those reported in the literature.
Table 3 Substrate scope using Wudaphos as the ligand ${ }^{a}$

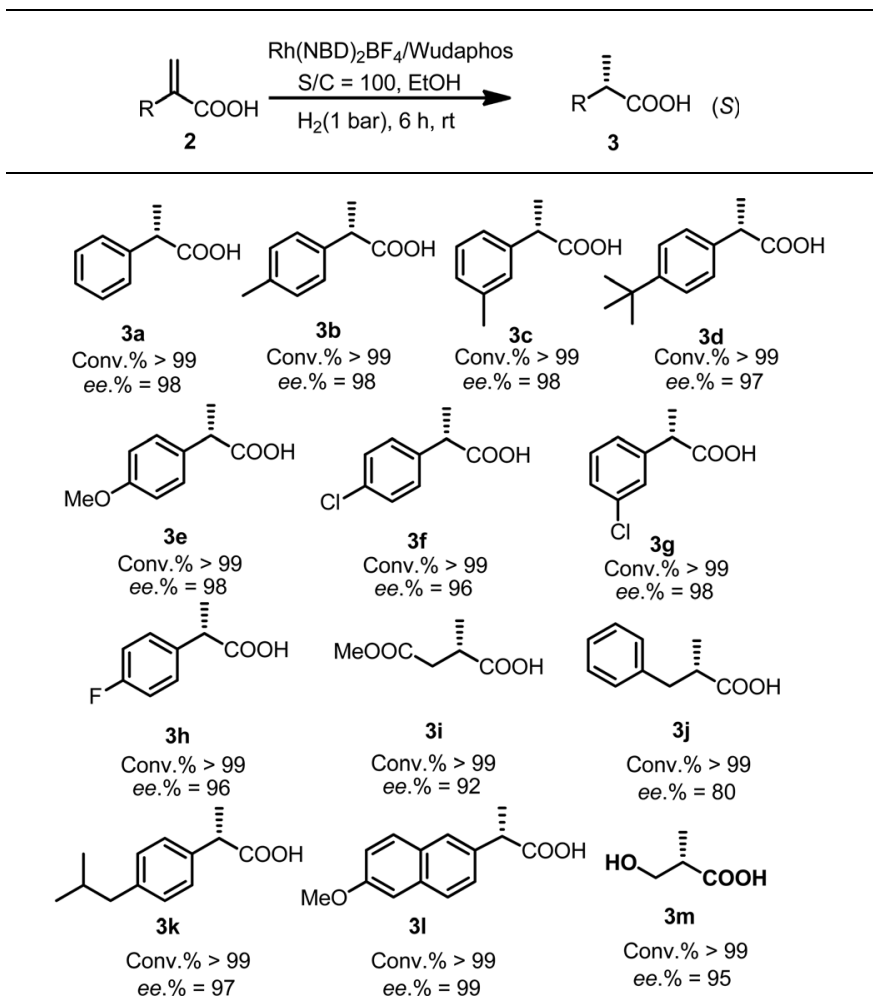

${ }^{a}$ The reaction was conducted in a $0.1 \mathrm{mmol}$ scale in $1 \mathrm{~mL}$ of $\mathrm{EtOH}$, $\left[\mathrm{Rh}(\mathrm{NBD})_{2}\right] \mathrm{BF}_{4} \quad(\mathrm{NBD}=$ norbornadiene $)$ was used as the metal precursor, Wudaphos was used as the ligand, $\mathrm{S} / \mathrm{C}=100, \mathrm{~L} / \mathrm{Rh}=$ $1.1: 1$, temperature $=\mathrm{rt}, \mathrm{H}_{2}$ pressure $=1 \mathrm{bar}$, reaction time $=6 \mathrm{~h}$, the configuration of all the product was determined as $(S)$ by comparing the optical rotation data with those reported by the literature, the $e e$ was determined via chiral HPLC after esterification with $\mathrm{CH}_{2} \mathrm{~N}_{2}$, and the conversion of the substrates was determined using ${ }^{1} \mathrm{H}$ NMR.

electron donating (Table 3, 3a-3e), electron withdrawing (Table 3, 3h), or halogens (Table 3, 3f-3h). 2-Alkyl acrylic acids were also smoothly hydrogenated with high $e e$ (Table $3, \mathbf{3 i}, \mathbf{3 j}$, $\mathbf{3 m})$. Thus, the intermediate for the preparation of Roche ester was conveniently obtained in high $e e$ (Table $3,3 \mathbf{3 m}$ ). Furthermore, the well-known anti-inflammatory drugs ibuprofen and naproxen were also easily obtained in excellent $e e$ under mild conditions (Table 3, 3k, 31). Our catalytic system shows a clear advance compared with the previous systems owing to its high enantioselectivity and base free conditions.

The asymmetric hydrogenation of 2-substituted acrylic acids was also conducted with low catalyst loading using 2 a as a model substrate under 50 bar $\mathrm{H}_{2}$ atmosphere. Satisfyingly, our catalyst system showed excellent activity under very mild conditions in the absence of any base when the catalyst loading was $0.02 \mathrm{~mol} \%(\mathrm{~S} / \mathrm{C}=5000)$ without any decrease of the $e e$ (Table 4, entry 1). Moreover, the hydrogenation also proceeded smoothly with full conversion and high $e e$ when lowering the catalyst loading to $0.01 \mathrm{~mol} \%(\mathrm{~S} / \mathrm{C}=10000$, Table 4 , entry 2$)$ or $0.005 \mathrm{~mol} \%(\mathrm{~S} / \mathrm{C}=20000$, Table 4 , entry 3$)$ albeit with a slight drop of ee. As shown in Scheme 5, the potent inhibitors 4 
Table 4 TON experiment with Wudaphos as the ligand $^{a}$<smiles>C=C(C(=O)O)c1ccccc1</smiles>

2a

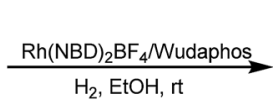

$\mathrm{H}_{2}, \mathrm{EtOH}, \mathrm{rt}$

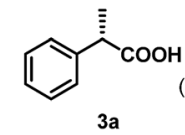

(S)

\begin{tabular}{lllll}
\hline Entry & S/C & Time $(\mathrm{h})$ & Conv. ${ }^{b_{\%}}$ & $e e^{c_{\%}}$ \\
\hline 1 & 5000 & 6 & $>99$ & 98 \\
2 & 10000 & 12 & $>99$ & 97 \\
3 & 20000 & 24 & $>99$ & 96
\end{tabular}

${ }^{a}$ The reaction was conducted in $\mathrm{EtOH},\left[\mathrm{Rh}(\mathrm{NBD})_{2}\right] \mathrm{BF}_{4}(\mathrm{NBD}=$ norbornadiene) was used as the metal precursor, Wudaphos was used as the ligand, $\mathrm{L} / \mathrm{Rh}=1.1: 1$, temperature $=\mathrm{rt}$, and $\mathrm{H}_{2}$ pressure $=50$ bar. ${ }^{b}$ Substrate conversion, determined via ${ }^{1} \mathrm{H}$ NMR. ${ }^{c}$ Enantiomeric excess of 3a, determined using chiral HPLC after esterification with $\mathrm{CH}_{2} \mathrm{~N}_{2}$.

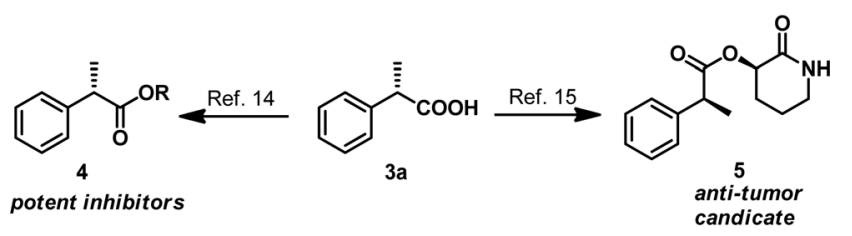

Scheme 5 Synthesis of the potent inhibitors 4 and the bioactive natural product 5 .

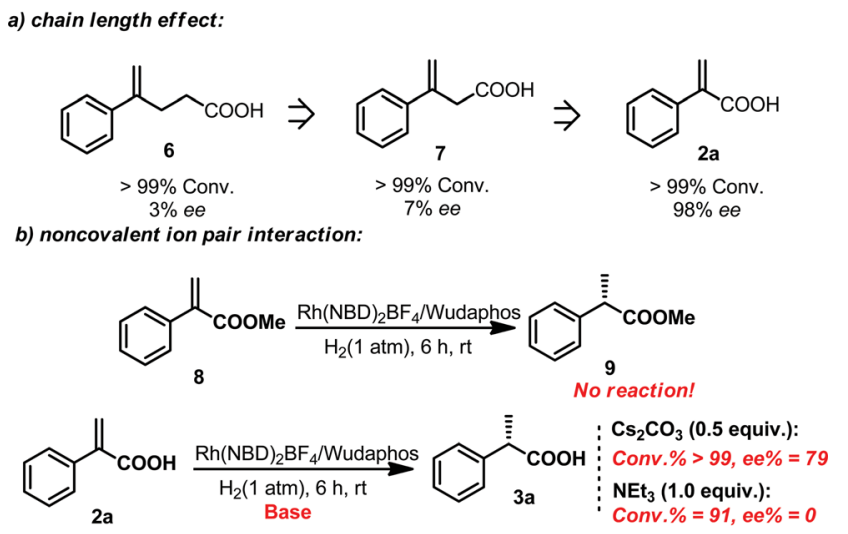

Scheme 6 Control experiments for the investigation of the chain length effect and the ion pair noncovalent interaction effect.

(ref. 14) and the bioactive natural product 5 (ref. 15) can be readily synthesized following literature procedures starting from the hydrogenation product $\mathbf{3 a}$.

In order to gain more insights into this catalytic system, several control experiments were also conducted. The effect of the chain length between the olefin and the acid moiety was first investigated. It was found that the chain length played an important role in determining the ee. Although the hydrogenation reactions of compounds $\mathbf{6 , 7}$ and $\mathbf{2 a}$ all proceeded smoothly, the ee obtained in the hydrogenation of 6 and 7 was very low (Scheme 6), which indicated that the excellent
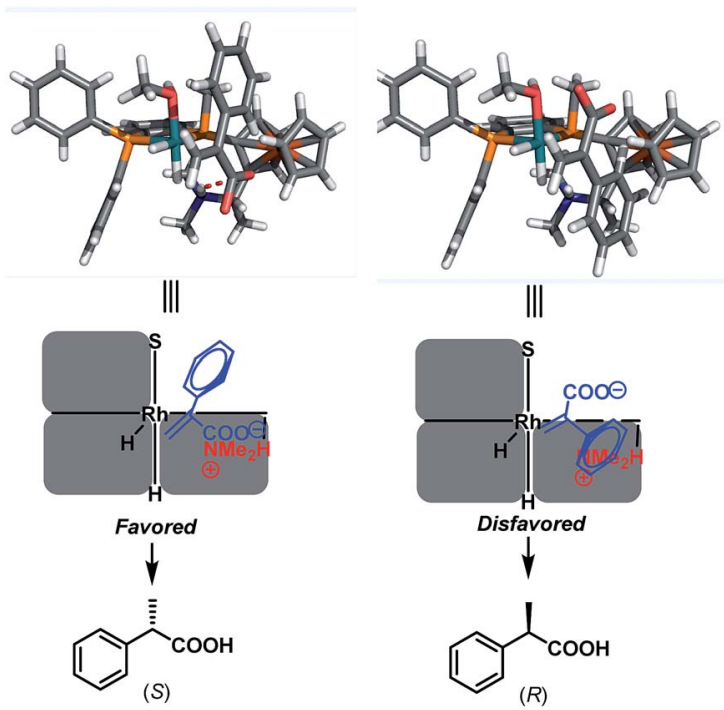

Scheme 7 3D models and the predicted enantiomeric control.

enantiomeric control was based on a matched chain length. Subsequently, the effect of the ion pair noncovalent interaction was also investigated. Hydrogenation of the ester substrate $\mathbf{8}$ did not occur at all. The $e e$ of the hydrogenation of $2 \mathrm{a}$ also dropped evidently when adding 0.5 equivalent of $\mathrm{Cs}_{2} \mathrm{CO}_{3}$. Moreover, only a racemic product was observed when one equivalent amount of triethylamine was added. It is probably due to the reason that the ion pair interaction between the ligand and substrate was interrupted by the additional base. These results suggested that the ion pair noncovalent interaction between the ligand and the acid substrates is critical (Scheme 6).

On the basis of the observed $(S)$-enantioselectivity, the X-ray crystal structure of ligand L1 (Scheme 1) and previous computational studies, ${ }^{21} 3 \mathrm{D}$ models were built to account for the important roles of the ion pair interaction and the small substituent on the phosphine ligand (Scheme 7). The favorable ionic pair interaction is present and the phenyl group on the substrate experiences less repulsion with the phosphine ligand for $(S)$-hydrogenation. In contrast, such an ionic pair interaction cannot form and the phenyl group on the substrate has larger repulsion with the ferrocenyl group for the $(R)$-hydrogenation. These 3D models also correspond to the hypothesis that we made that the good enantiomeric control of the Wudaphos is based on the three hindered quadrant model.

\section{Conclusions}

In summary, a new class of ferrocenyl chiral bisphosphorus ligand, Wudaphos, was developed. The Wudaphos type ligands are highly air stable and exhibit excellent $e e$ and activity ( $e e$ up to $99 \%$, TON up to 20000 ) for the asymmetric hydrogenation of both 2-aryl and 2-alkyl acrylic acids. Importantly, the hydrogenation reaction was efficiently realized through the attractive ion pair noncovalent interaction in base free and mild reaction conditions, which shows a clear advance compared with the 
previous catalytic system. Well-known anti-inflammatory drugs such as naproxen and ibuprofen together with the intermediate for the preparation of Roche ester and some bioactive compounds were efficiently obtained with an excellent $e e$. Control experiments were conducted and revealed the ion pair noncovalent interaction played an important role and the excellent enantiomeric control was based on the matched chain length between the olefin and the acid moiety.

\section{Acknowledgements}

We are grateful for the financial support by the grant from Wuhan University (203273463, 203410100064), “111" Project of the Ministry of the Education of China and the National Natural Science Foundation of China (Grant No. 21372179, 21432007, 21502145).

\section{Notes and references}

1 (a) W. Tang and X. Zhang, Chem. Rev., 2003, 103, 3029; (b) Comprehensive Asymmetric Catalysis, ed. E. N. Jacobsen, A. Pfaltz and H. Yamamoto, Springer, Berlin, 1999.

2 (a) J.-H. Xie, S.-F. Zhu and Q.-L. Zhou, Chem. Rev., 2010, 111, 1713; (b) Comprehensive Chirality, ed. H. Yamamoto and E. Carreira, Elsevier, 2012; (c) Stereoselective Synthesis, ed. R. S. Atkinson, Wiley, 1995.

3 R. R. Knowles and E. N. Jacobsen, Proc. Natl. Acad. Sci. U. S. A., 2010, 107, 20678.

4 M. Sawamura and Y. Ito, Chem. Rev., 1992, 92, 857.

5 (a) W. Chen, P. J. McCormack, K. Mohammed, W. Mbafor, S. M. Roberts and J. Whittall, Angew. Chem., Int. Ed., 2007, 46, 4141; (b) W. Chen, F. Spindler, B. Pugin and U. Nettekoven, Angew. Chem., Int. Ed., 2013, 52, 8652.

6 A. Togni, C. Breutel, A. Schnyder, F. Spindler, H. Landert and A. Tijani, J. Am. Chem. Soc., 1994, 116, 4062.

7 W. Weissensteiner, T. Sturm and F. Spindler, Adv. Synth. Catal., 2003, 345, 160.

8 M. Lotz, K. Polborn and P. Knochel, Angew. Chem., Int. Ed., 2002, 41, 4708.

9 N. W. Boaz, S. D. Debenham, E. B. Mackenzie and S. E. Large, Org. Lett., 2002, 4, 2421.

10 A. J. J. Perea, A. Borner and P. Knochel, Tetrahedron Lett., 1998, 39, 8073.

11 M. Sawamura, H. Hamashima, M. Sugawara, N. Kuwano and Y. Ito, Organometallics, 1995, 14, 4549.

12 (a) G. Hoge, H. Wu, W. S. Kissel, D. A. Pflum, D. J. Greene and J. Bao, J. Am. Chem. Soc., 2004, 126, 5966; (b) K. Huang, X. Zhang, T. J. Emge, G. Hou, B. Cao and X. Zhang, Chem. Commun., 2010, 46, 8555.

13 (a) D. Lednicer and L. A. Mitscher, The Organic Chemistry of Drug Synthesis, Wiley, New York, 1977, vol. 1; D. Lednicer and L. A. Mitscher, The Organic Chemistry of Drug Synthesis, Wiley, New York, 1980, vol. 2; (b) T. Y. Shen, Angew. Chem., Int. Ed., 1972, 11, 460; (c) P.-J. Harrington and E. Lodewijk, Org. Process Res. Dev., 1997, 1, 72.
14 S. Tchilibon, J. Zhang, Q.-F. Yang, O. Eidelman, H. Kim, H. Caohuy, K. A. Jacobson, B. S. Pollard and H. B. Pollard, Biochem. Pharmacol., 2005, 70, 381.

15 P. R. Krishna, P. V. A. Kumar, V. S. Mallula and K. V. S. Ramakrishna, Tetrahedron, 2013, 69, 2319.

16 (a) Y. Tu, M. Ni, Y. Zhong, L. Li, S. Cui, M. Zhang, X. Wang and X. Liang, Yaoxue Xuebao, 1981, 16, 366; (b) R. W. Burg, B. M. Miller, E. E. Baker, J. Birnbaum, S. A. Currie, R. Hartman, Y. R. Kong, L. Monaghan and G. Olson, Antimicrob. Agents Chemother., 1979, 15, 361; (c) J. R. Egerton, D. A. Ostlind, L. S. Blair, C. H. Eary, D. Suhayda, S. Cifelli, R. F. Riek and W. C. Campbell, Antimicrob. Agents Chemother., 1979, 15, 372.

17 (a) S. J. Mickel, G. H. Sedelmeier, D. Niederer, F. Schuerch, G. Koch, E. Kuesters, R. Daeffler, A. Osmani, S. Weibel, M. E. Schmid, A. Hirni, K. Schaer and R. Gamboni, Org. Process Res. Dev., 2004, 8, 107; (b) I. Paterson, O. Delgado, G. J. Florence, I. Lyothier, M. O. Brien, J. P. Scott and N. Sereinig, J. Org. Chem., 2005, 70, 150.

18 (a) T. Ohta, H. Takaya, M. Kitamura, K. Nagai and R. Noyori, J. Org. Chem., 1987, 52, 3174; (b) Q.-H. Fan, C.-Y. Ren, C.-H. Yeung, W.-H. Hu and A. S. C. Chan, J. Am. Chem. Soc., 1999, 121, 7407; (c) C.-C. Pai, C.-W. Lin, C.-C. Lin, C.-C. Chen and A. S. C. Chan, J. Am. Chem. Soc., 2000, 122, 11513; (d) Q.-H. Fan, Y.-M. Chen, X.-M. Chen, D.-Z. Jiang, F. Xi and A. S. C. Chan, Chem. Commun., 2000, 789; (e) R. A. Brown, P. Pollet, E. McKoon, C. A. Eckert, C. L. Liotta and P. G. Jessop, J. Am. Chem. Soc., 2001, 123, 1254; $(f)$ G.-J. Deng, B. Yi, Y.-Y. Huang, W.-J. Tang, Y.-M. He and Q.-H. Fan, Adv. Synth. Catal., 2004, 346, 1440; (g) L. Qiu, F. Y. Kwong, J. Wu, W. H. Lam, S. Chan, W.-Y. Yu, Y.-M. Li, R. Guo, Z. Zhou and A. S. C. Chan, J. Am. Chem. Soc., 2006, 128, 5955; (h) L. Qiu, Y.-M. Li, F. Y. Kwong, W.-Y. Yu, Q.-H. Fan and A. S. C. Chan, Adv. Synth. Catal., 2007, 349, 517.

19 (a) F. Robin, F. Mercier, L. Ricard, F. Mathey and M. Spagnol, Chem.-Eur. J., 1997, 3, 1365; (b) B. Zupančič, B. Mohar and M. Stephan, Adv. Synth. Catal., 2008, 350, 2024; (c) M. S. Tephan, D. Šterk and B. Mohar, Adv. Synth. Catal., 2009, 351, 2779; (d) B. Zupančič, B. Mohar and M. Stephan, Org. Lett., 2010, 12, 1296; (e) B. Zupančič, B. Mohar and M. Stephan, Org. Lett., 2010, 12, 3022; (f) Y. Zhang, Z.-B. Han, F.-Y. Li, K.-L. Ding and A. Zhang, Chem. Commun., 2010, 46, 156; (g) S.-F. Zhu, Y. Yu, S. Li, L. Wang and Q.-L. Zhou, Angew. Chem., Int. Ed., 2012, 51, 8872; (h) K. Dong, Y. Li, Z. Wang and K. Ding, Org. Chem. Front., 2014, 1, 155.

20 The X-ray crystal data of $\mathbf{L 1}$ has been deposited with the Cambridge Crystallographic Data Centre as supplementary publication no. CCDC 1456993. $\dagger$

21 I. D. Gridnev and T. Imamoto, ACS Catal., 2015, 5, 2911, and references therein. 